\title{
Preprint
}

\section{Scaring away anxiety: Therapeutic avenues for horror fiction to enhance treatment for anxiety symptoms}

\author{
Coltan Scrivner ${ }^{1,2}$ \\ Kara A. Christensen ${ }^{3}$ \\ 1Department of Comparative Human Development, The University of Chicago, Chicago, \\ IL 60606 USA \\ ${ }^{2}$ Institute for Mind and Biology, The University of Chicago, Chicago, IL 60606 USA \\ ${ }^{3}$ Department of Psychology, University of Kansas, Lawrence, KS 66045 USA
}

\begin{abstract}
From scary stories to horror films and haunted houses, the horror genre is wildly popular. Although horror aims to elicit fear and anxiety in its audience, many people with anxiety are horror fans and some report using horror to cope with their anxiety. In this article, we provide a theoretical rationale for why people with anxiety might choose to access and find relief in horror films. First, we discuss aspects of horror that could make it particularly alluring to people with anxiety and how the use of horror may be negatively reinforcing. Next, we examine how engagement with horror could be used to build skills for resilience in more generalized situations. We build on processes from evidence-based therapies (i.e., cognitive behavioral therapy and exposure therapy) to explain how horror media has the potential to be used as a therapeutic tool. Finally, we discuss steps for future research on horror as a therapeutic tool for anxiety-related disorders.
\end{abstract}




\section{Background on Recreational Horror}

\section{The Paradox of horror}

Humans derive seemingly paradoxical enjoyment out of scaring themselves. Though the beginnings of the horror genre are often traced to gothic literature in the mid-18th century, horror stories extend much further back in human history. Some of the earliest examples of writing include tales of monsters, ghosts, haunted spaces (Asma, 2009; Felton, 2010). From scary stories to horror films and haunted houses, the horror genre is wildly popular. Instead of avoiding situations that elicit typically negative emotions such as fear and anxiety, many people intentionally seek out these situations. This bizarre behavior has puzzled some of the world's greatest thinkers. Why would people purposely seek out fiction that makes them feel afraid or anxious?

More than 2000 years ago, Aristotle mused that tragedy was popular because it allowed people to purge themselves of difficult emotions such as pity and fear (Aristotle, 2006). David Hume also observed that sorrow, anxiety, and terror seem to make certain spectacles more enjoyable (Hume, 1971). These early speculations have led to modern scholarly work on what is now known as the paradox of horror - the seemingly paradoxical phenomenon where people seek out situations that elicit anxiety, fear, and disgust. Some modern scholars argue that people do not actually enjoy the negative emotions themselves, but rather the curiosity that is aroused from the unfamiliar (Carroll, 2003). However, others have argued that people can enjoy negative emotions themselves rather than simply tolerate them as collateral damage for curiosity (Gaut, 1993).

In this paper, we will explore some of the psychological theories behind why horror media is popular among a group of people for whom this paradox would seem particularly salient: people with elevated symptoms of anxiety. We further discuss how horror is a unique tool that can be used within evidence-based therapies to educate and challenge clients to face their fears and offer suggestions for incorporating horror media into cognitive-behavioral therapy and exposure therapy. Figure 1 provides a visual summary of our argument.

\section{Personality and horror}

Though a majority of people report enjoying horror films (Clasen et al., 2020), certain personality types and individual differences tend to correlate with horror fandom. One of the most consistent personality correlates of horror fandom is sensation seeking (Martin 2019). Sensation seeking may be described as a tendency to seek out experiences that maximize arousal through novelty, complexity, or intense sensations (Zuckerman, 1994). In a large study on the personality of horror fandom, Clasen et al. (2020) found that horror fans were more likely to be high in sensation-seeking and intellect/imagination (openness to experience in the Big Five Inventory). Still, these 
findings are not without caveats. Some measures of behavior, such as horror film attendance, are only weakly correlated with sensation seeking (Tamborini \& Stiff, 1987). Moreover, the relationship between overall sensation seeking and horror attendance may not be significant for women, and different subscales predict horror film attendance differently for men and women (Cantor \& Sparks, 1984; Zuckerman \& Litle, 1986).

One of the strongest predictors of horror fandom that has been found is trait morbid curiosity (Scrivner, 2020). Morbid curiosity is defined as an interest in seeking information about potentially threatening material. In horror films, morbidly curious people can experience relatively low-cost, simulated experiences with danger that would otherwise be difficult or dangerous to learn about. For example, what are "psychopathic" serial killers like in their day-to-day life? What does a "possessed" person look or act like? If vampires existed, how could they be identified and defeated? Exposure to these fictional terrors triggers deeply rooted fears in human psychology (Clasen, 2017). Vampires, zombies, and werewolves are not real threats, but they possess characteristics of real threats - sharp teeth, infectiousness, disregard for human life, etc.

When certain threats are salient in the real world, morbidly curious people may seek out information about that threat through horror fiction. For example, morbid curiosity was associated with watching more horror and pandemic-themed movies than usual during the COVID-19 pandemic (Scrivner, 2021). In fact, morbidly curious people may be partially responsible for the meteoric rise in popularity of Contagion during the early months of the COVID-19 pandemic. By watching movies that simulated the world during or after a catastrophic event, viewers can gather information about what the world looks like and how people might behave during catastrophic events. In turn, this may lead to a feeling of preparedness and resilience in the face of fearful situations in the real world (Scrivner et al., 2021).

\section{The Overlap Between Anxiety Pathology and Horror Fandom}

\section{Overview of anxiety}

Though anxiety and fear are phenomenologically similar and often conflated, anxiety is best characterized as a response to an uncertain or potential threat whereas fear can be characterized as a response to an observable, immediate, or concrete threat (Bouton et al., 2001; Mobbs et al., 2015). While fear is an emotion that evolved to aid in avoiding a present threat, anxiety has evolved to protect our species from uncertain or future threats. The emotion of anxiety is typically characterized by increased physiological arousal (e.g., racing heart, increased breath rate) and worry or uneasy apprehension about an anticipated future event (e.g., Spielberger, 1966). 
A certain level of anxiety is adaptive and necessary to respond adequately to the challenges of life (e.g., Gutierrez-Garcia \& Contreras, 2013; Nesse, 2019); however, when anxiety is experienced in inappropriate contexts and/or causes significant impairment over time, it may rise to the level of a clinical disorder (American Psychiatric Association, 2013). The obvious manifestation of this is in the anxiety disorder diagnostic category (compromising conditions such as generalized anxiety disorder, specific phobia, agoraphobia, panic disorder, and social anxiety disorder); however, other internalizing disorders such as mood disorders, obsessive-compulsive and related disorders, eating disorders (e.g., Schaumburg et al., 2020), and post-traumatic stress disorder (which was listed in DSM-IV-TR as an anxiety disorder, e.g., Pai, Suris, \& North, 2017) also feature heightened levels of anxiety.

Anxiety in the context of these psychological disorders is persistent, often difficult to control, and can be generalized (e.g., worry about the future) or disorder-specific (e.g., worry about weight gain, in the case of eating disorders). Individuals with clinical symptoms of anxiety tend to experience worry or apprehension that is out of proportion to the threat posed by the situation, which results in difficulty with relationships, work, school, or personal functioning. In some cases, anxiety is accompanied by physiological arousal or symptoms (e.g., muscle tension). Notably, people with anxiety symptoms often experience their worries as difficult to control, time-consuming, and intrusive, which increases distress and impairment.

In general, anxiety tends to be associated with avoidant behavior, with many theories suggesting that anxiety disorders are reinforced through the repeated avoidance of situations that elicit distress (e.g., Salters-Pedneault \& Roemer, 2004). Some have theorized, however, that in certain circumstances, avoidance can serve adaptive functions, as it may allow people to regain a sense of control over themselves and the environment, thereby enabling them to increase their willingness to approach future anxiety-provoking situations (e.g., Hoffman \& Hay, 2018). In other words, avoidance can serve maladaptive and adaptive functions, depending on how it influences future behavior. The paradox of horror may be less paradoxical if one considers that engaging with horror content could be a form of avoidance. Specifically, engaging with horror content may be less aversive than engaging with intrusive thoughts or worries for people with elevated anxiety and in fact, may reduce anxiety in the short-term. However, to evaluate maladaptive and adaptive functions of horror, it is important to consider if engagement with horror prioritizes short-term distress reduction over long-term learning and carefully evaluate this balance in terms of an individual's global functioning and priorities.

\section{The role of anxiety in recreational horror}

Recreational horror may be defined as a mixed emotional experience of fear and enjoyment (Andersen et al., 2020). However, we add to this definition the emotion of 
anxiety. While fear is commonly associated with horror, anxiety is arguably as important to the experience. Certain experiences during recreational horror such as the "jumpscare" (e.g., when the killer appears suddenly in frame), are intended to elicit instances of acute fear. However, people who engage with recreational horror through books, podcasts, movies, and haunted houses know going into the experience to expect frightening situations to occur. The knowledge that frightening situations are looming produces a sense of anxiety throughout the experience, what Stephen King (2010) calls "the terror." The audience knows to expect a jump-scare - but they do not know when it will occur or what it will look like, leading to a feeling of suspense or anxiety throughout the film.

Moments of acute fear scattered throughout a movie can also keep the audience on their toes, feeding them a steady drip of anxiety throughout the experience. Indeed, a horror film may be best characterized by both the acute fear it induces in momentary jump-scares and by the feeling of anxiety it incites throughout - creating a sort of atmosphere of dread. In order to maximize the feeling of anxiety, filmmakers will often cue the audience that a jump-scare is coming. Some of the most iconic jump-scares get their power through a tense build-up of music and a scene setup that informs the audience that a scare is imminent. The anxiety-inducing moments of a horror film often serve to make the film more popular and revered as a "good" horror film.

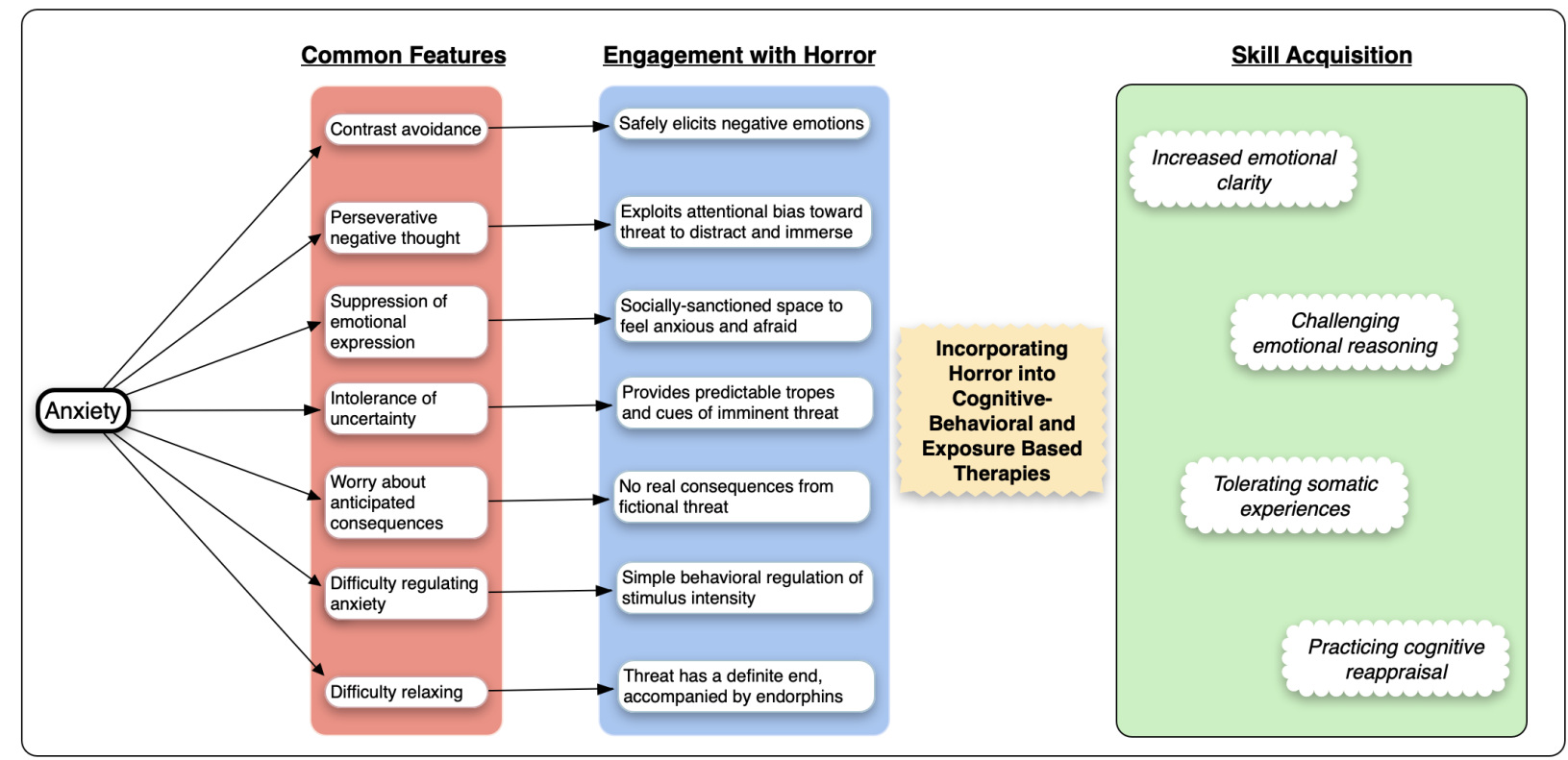

Figure 1. Summary of how horror can help with anxiety in the moment and build resilience for more generalized situations. 


\section{The allure of horror to someone with anxiety}

Despite the fact that horror aims to elicit fear and anxiety in its audience, some horror fans report using horror to deal with clinical anxiety (e.g., see Grisafi, 2016; Turner, 2017). Anecdotal reasons for this behavior often relate to a desire to have control over feelings of anxiety. However, to our knowledge, empirical studies have yet to be conducted on this phenomenon. Some individuals with PTSD also report "selftriggering," where they remind themselves of their trauma through films, books, and other methods. One study by Bellet et al., 2020 found that this behavior is not uncommon among individuals who have experienced trauma. Much like the anecdotal reports of using horror as a way to control feelings of anxiety, many participants in Bellet et al.'s study reported self-triggering as a way to control their PTSD. Other reasons for self-triggering included a desire to match external experiences with internal states (i.e., affect matching) and to make meaning out of their traumatic experiences.

Morbid curiosity may explain part of the seemingly paradoxical attraction of horror to people with anxiety. At its core, morbid curiosity is a trait that inspires one to seek out information about threatening situations, presumably as a proactive method to prepare for threats. This information could come from a variety of sources and may not need to be related to something that actually happened. Stories, even if they are fictional, can provide accurate descriptions of possible events (Barber \& Barber, 2004). In fact, fictional stories are uniquely positioned to provide important information that is otherwise inaccessible because they can be tailored to specific situations and take into account relevant contextual information (Scalise-Sugiyama, 2020). Horror stories focus on a particular type of information - knowledge about threatening situations. Horror stories convey information about potentially dangerous situations or phenomena, detailing what these situations look like, how people tend to respond, and what behaviors and actions are successful.

The information presented in horror media is also likely to draw the attention of someone with anxiety. Evolutionary scientists have long argued that anxiety, at its core, evolved to prepare individuals to detect and prepare for threats (Bateson et al., 2011; Marks \& Nesse, 1994). Central to this is the detection and consumption of information about threats. Thus, like morbid curiosity, anxiety may compel people to seek out information about threats in the form of stories. Because of this, attraction to horror stories is a reliable indicator of high trait morbid curiosity - and potentially of high anxiety.

Though the attraction of horror to individuals who feel anxious has received little attention in psychology, a few studies have reported finding a relationship between anxiety and horror entertainment. Over the course of one week, Strizhakova and Krcmar (2007) had customers who were entering a video rental store report their current mood states. After making their choices in the store, participants returned to researchers and reported which movies they had rented. To the surprise of the 
researchers, customers who felt nervous were much more likely to have rented horror movies. Thus, this study suggests that feeling anxious or nervous might lead one to seek out entertainment that matches this feeling.

A recent big data study using Facebook likes, personality data collected through the myPersonality Facebook app, and movie plot keywords from IMDB suggests that trait anxiety may also be related to horror fandom. Nave et al. (2020) found that fans of horror movies (indicated by Facebook likes) were more likely to score high in trait neuroticism - a personality trait characterized by high anxiety. The researchers also discovered that anxiety-related plot keywords such as "mental illness," "ghost," "serial killer," and "insanity" were among the strongest predictors of fans' neuroticism. Plot keywords were further used to identify 35 psychological themes (e.g., death, friends, religion, health, etc.). From this, Nave et al. also found that psychological themes of death and anxiety predicted high neuroticism among fans of those movies. In other words, people who are high in trait anxiety are often fans of movies with anxietyinducing plots.

The desire to experience anxiety may be particularly salient for some people with generalized anxiety disorder (GAD), the hallmark of which is uncontrollable, intrusive worry. The Contrast Avoidance Model of GAD (Newman \& Llera, 2011) posits that people with GAD experience discomfort when shifting from neutral or positive emotions to negative emotions (negative contrasts), therefore they engage in worry to maintain elevated negative affect. At the same time, more frequent negative affect through worry leads to increased probability of positive contrasts, such that a person experiences relief when the feared (but improbable) event does not occur (e.g., Rashtbari \& Saed, 2020). Along these lines, it is possible that people who are elevated in anxiety may experience a preference for horror media because it safely and predictably elicits negative emotions, allowing them to generate and maintain heightened negative affect. Furthermore, horror media sets one up to experience a positive contrast when the viewer experiences heightened negative affect that is then resolved when the film ends and the viewer is unharmed.

Given that people with high anxiety report greater liking of horror, one can assume that there are processes that reinforce engagement with this content. In the following paragraphs, we describe several hypotheses about how engagement with horror media may reduce anxiety in the moment (Table 1 ), which could serve as a negative reinforcement method. In the following section, it is important to emphasize that it is critical to consider the long-term adaptiveness of engaging with horror content, particularly because more research is required to disentangle short-term from long-term goals of behaviors related to emotion regulation (e.g., Aldao \& Christensen, 2015; Christensen \& Aldao, 2015). In some cases, engagement with horror content may result in learning that leads to increased resilience, generalization to non-horror stimuli, and reduced avoidance; however, it is equally possible that, for some individuals, these 
behaviors reinforce maladaptive cognitions and behaviors and may maintain symptoms of anxiety. Consequently, evaluating both short and long-term effects of these processes is critical for evaluating which behaviors should be encouraged or discouraged.

\section{How Horror May Reduce Anxiety in the Moment}

\section{The centrality of threat leads to immersion}

At the core of the horror film is a threat. In many cases, the threat in a horror film is present in the form of a monster or a human who might be considered monstrous. Typically, this threat fulfills the purpose of the horror film - to inspire fear and anxiety in the viewer. It is also the centrality of a physical threat to the plot that might make the horror film particularly alluring for the anxious individual.

All humans display an attentional bias toward threat (Cisler et al., 2009; Koster et al., 2004; Mobbs et al., 2015). This predisposition occurs from a young age (LoBue \& Rakison, 2013) and includes stimuli such angry faces (Hansen \& Hansen, 1988; LoBue, 2009), predators (Ohman et al., 2001; Penkunas \& Coss, 2013), and violent contact (Scrivner et al., 2019). The primacy of threat to human cognition can also be seen in the social transmission of information (Blaine \& Boyer, 2018; Davis \& McLeod, 2003), learning (Barrett \& Broesch, 2015; Wertz, 2019), and memory (Kensinger, 2007; Nairne et al., 2007). Monitoring the threat and determining the best course of action is part of a suite of neural systems that optimize survival and threat reduction in animals, including humans (Blanchard et al., 2010; Mobbs et al., 2005; Neuberg et al., 2011).

Given the attentional premium that is placed on salient threats and the centrality of threat to horror plots, horror films are likely to be especially good at drawing the attention of audiences. Just as we have trouble looking away from a violent fight or a car accident, we also have trouble looking away from a fictionalization of dangerous events. Even if the event has yet to occur, the audience knows that threat is imminent in a horror film. This knowledge harnesses the mind's threat management system, increasing vigilance and surveillance of the environment. Moreover, the attention bias toward threat is even stronger among those with high anxiety (Bar-Haim et al., 2007; Pergamin-Hight et al., 2015).

Increased vigilance may also lead to increased immersion in the story. In a study using virtual reality, Bouchard et al. (2008) found that anxiety-inducing environments increased feelings of immersion compared to control environments. Likewise, a metaanalysis by Ling et al (2014) found that individuals with a diagnosed anxiety disorder felt more present during virtual reality exposure therapy than those without a clinical diagnosis. These studies suggest that threatening situations hold an even stronger grip on attention and immersion for anxious individuals. Because of this, horror films may be 
uniquely positioned to draw the attention of anxious viewers and immerse them in the plot. This immersion may serve as a potent distraction from rumination or worry about real-world problems that commonly occurs in people experiencing anxiety.

\section{Horror provides a space to be anxious}

Anxiety experienced in the context of horror may also be an outlet for people who experience pressure to conceal, or suppress, their emotions. Expressive suppression is a commonly employed emotion regulation technique in which individuals attempt to conceal the outward expression of emotions (e.g., Gross, 1998); however, it is not particularly effective at down-regulating negative affect, as it tends to result in rebounds in anxiety (e.g., Campbell-Sills et al., 2006, Gross \& John, 2003). Habitually suppressing expression may lead to poorer social functioning because a gap is created between true internal experience and outwards expression that affects both the individual (e.g., English and John, 2013) and those with whom they interact (e.g., Butler et al., 2003). Importantly, greater habitual use of emotional suppression is associated with increased symptoms of anxiety disorders (Aldao, Schweizer, \& Nolen-Hoeksema, 2010), suggesting that this is a common problematic behavior in people high in anxiety.

Expressive suppression may be undertaken for a variety of motivations, including cultural and individual beliefs about the appropriateness of emotional expression. These beliefs include, but are not limited to, beliefs that showing emotions reflects weakness, emotions should be controlled, and emotion expression could lead to rejection. Indeed, in one study, these beliefs mediated the association between social anxiety and the use of emotional suppression (Spokas, Luterek, \& Heimberg, 2009). Thus, for people who frequently engage in expressive suppression due to beliefs about the acceptability of showing emotions, horror content may provide socially sanctioned outlets for experiencing high levels of anxiety and fear, even though in real life elevated anxiety is stigmatized (Curcio \& Corboy, 2020). In other words, when one is watching a horror movie, it is considered appropriate to be anxious about the sound of footsteps in the abandoned building, but expressing such worries in daily life may be perceived negatively. Thus, engaging with horror content could provide a way to experience and express emotions for people with anxiety who feel pressure to hide how they are feeling.

\section{Horror provides a predictable source for feelings of anxiety}

Furthermore, horror content may provide clarity for people who frequently worry by offering an easily identifiable source of negative emotions. Many individuals with elevated anxiety show an intolerance to uncertainty, such that they find uncertain situations to be stressful and, thus, to be avoided (e.g., Dugas, Freeston, \& Ladouceur, 1997). Intolerance of uncertainty has been linked using meta-analyses to generalized anxiety disorder (Gentes \& Ruscio, 2011), eating disorders (Brown et al., 2017), 
obsessive-compulsive disorder (Gentes \& Ruscio, 2011), and major depressive disorder (Gentes \& Ruscio, 2011), leading to its conceptualization as a transdiagnostic risk factor for psychopathology (Einstein, 2014). Although specific details of horror content may be uncertain, the tropes of horror provide a sense of "certain uncertainty" for the viewer, as they set a template of what the viewer can expect if certain elements are present. For example, the viewer may not know when a jump-scare will occur, but music in the movie can notify the audience that something frightening is imminent and direct them to be vigilant (Ansani et al., 2020). Another example is the mirror trope, in which a character looks in a mirror or reflective surface, there is a cutaway, and then the camera returns to the mirror to reveal that the killer or monster is behind the character. Similarly, uncertainty about the fate of the lead character may be resolved if the viewer knows the main female character ("final girl") is likely to survive to the end of the film (see review of "final girl" trope in Paszkiewicz \& Rusnak, 2017). Thus, such tropes may allow the person with anxiety to engage with uncertainty, without feeling like they do not have control, as they have a sense for what is likely to happen next in the film.

\section{Transferring anxiety to a fictional source}

Because it is acceptable and even expected that one will feel anxious while watching a horror film, viewers can fully express their feelings of anxiety without the social consequences that sometimes accompany these feelings. Moreover, the feelings of anxiety that were once rooted in a real-world event or may have had an unknown source can be transferred to the threat on the screen. In other words, the threat on the screen captures the attention of the viewer, becoming an alternative source for the feelings of anxiety that the viewer is feeling. With the source of anxiety now existing in the movie, the viewer has some sense of psychological distance from and control over the threat (further explained in the next section). However, the horror film itself does not reduce anxiety in the viewer. In fact, it should be a relatively potent source of anxiety in order for this process to work. In this way, the horror film becomes a new, more controllable source of the anxiety.

Once the main source of anxiety is identified as being some aspect of the horror film, the viewer gains a sense of control over the source of the anxiety. This sense of control is a key aspect of why horror may be a good conduit for regulating anxiety. Decades of research in non-human animals has shown the negative effects of a lack of control over stressors (see Maier \& Seligman, 2016 for review). In humans, increasing perceived control over a stressor appears to reduce activation in areas of the brain that respond to threat-related uncertainty (Limbachia et al., 2021) and attenuate anxiety (Salomons et al., 2015). When feeling anxious, people often have little perceived control over their anxiety. However, when feeling anxious due to a horror film, viewers have several avenues of potential control or regulation over the source of the anxiety. 


\section{Increased control and regulation of anxiety}

Anxiety is largely baked into the suspense that leads up to the jump-scares (or predicted jump-scares, even if one does not occur). However, this suspense and the accompanying arousal can be attenuated in a variety of ways. For example, viewers feeling too anxious can watch a movie with the lights on or volume turned down. These tactics serve to decrease immersion which, while necessary to initially draw the viewer in, may need to be down-regulated in certain parts of the movie for an optimal experience. The viewer also has some control over the threat itself. Once the monster makes an appearance on-screen, simple behaviors like covering one's eyes can reduce fear and lead to a feeling of control over the situation. Thus, horror fiction produces anxiety that is controllable by the viewer in a way that is difficult or impossible when the source of anxiety is tied to something in the real world or has an unidentifiable source. Feeling anxious -- and the degree to which you feel anxious -- becomes a choice on the part of the viewer when watching a horror movie rather than something that is happening outside of their control.

It is perhaps a common misconception that all horror fans necessarily want more fear. Instead, horror fans appear to regulate their arousal levels for an optimal experience. In a field study at a haunted house, Clasen et al. (2019) found that haunted house attendees used a suite of cognitive, behavioral, and social strategies to upregulate and down-regulate their fear levels throughout the experience. Down-regulation strategies included things such as imagining that the scary aspects were not real, finding humor in the situation, looking away from the scare actors, and physically holding onto friends. "Adrenaline junkies" who attempted to increase arousal upregulated arousal by using strategies such as focusing on the scares, imagining that the situation could be real, engaging in the narrative, and letting themselves scream. Regardless of the strategies used, enjoyment levels remained about equal. This suggests that haunted house attendees may attempt to regulate arousal to achieve their optimal level. Indeed, another study by Andersen et al. (2020) found that there is a "sweet spot" for physiological arousal in haunted house attendees at which enjoyment is maximized. These studies suggest that horror offers an opportunity for people to engage with high-arousal, anxiety-inducing content in a way that allows a sense of control over the situation.

\section{Possible calming effects of horror}

Unlike anxiety stemming from the real world, horror fiction-induced anxiety is rooted in a clear source, is more easily managed, and has a clear timeframe. Though empirical evidence on the neurochemical effects of "surviving" a horror experience are lacking, some studies have reported post-experience mood boosts in people who engage with recreational fear (Kerr et al., 2019; Author et al., in prep). Likewise, participant anxiety levels in Kerr et al. were lower after the haunt than before, 
suggesting resolution of the haunted attraction does lead to a decrease in anxiety. In addition, Kerr et al. found that participants displayed widespread decreases in neural reactivity after completing the haunt. This converges well with anecdotal evidence from people who engage with recreational horror and mention feeling a "comedown" after the experience ends.

The physiological changes and accompanying mood changes that occur after a horror film may resemble those that occur following aerobic exercise. Aerobic exercise may induce what is sometimes referred to as a "runner's high," which is a euphoric feeling following exercise. Studies in rodents and humans have implicated both endorphin (Boecker et al., 2008) and endocannabinoid (Fuss et al., 2015) activity as mechanisms for the euphoric feeling. Similar to exercise, horror movies and other "funscary" experiences can upregulate sympathetic nervous system activity, resulting in increased heart-rate, perspiration, respiration, and cortisol release. Given the similarities in sympathetic nervous system activation between exercise and fun-scary experiences, some of the same mechanisms may mediate the mood boosts and decreased neural reactivity following engagement with recreational horror. Future research should work to identify possible mechanisms of mood change during recreational horror experiences.

Table 1. Negative reinforcement processes that may increase or maintain engagement with horror media.

\section{Anxiety Concept Explanation How Horror Helps in the Moment}

negative thought

People experiencing elevated anxiety may have difficulty disengaging from negative thought patterns

Individuals with elevated

Suppression of emotional expression

Intolerance of uncertainty anxiety often suppress feelings of anxiety to avoid social consequences

Intolerance of uncertainty is a key risk factor for anxiety, and feelings of uncertainty can increase anxiety
Threat is a key plot device in horror. Because anxiety amplifies attentional biases to threat, horror movies could distract and immerse people with anxiety in the plot. Anxiety may be transferred from the real world to the fictional world of the film.

It is socially acceptable to express fear and anxiety during a horror film. Horror offers a socially-sanctioned space for people to express their emotions.

Horror movies often contain predictable tropes. Cues such as tense music alert the viewer to imminent jump-scares. 
Worry about anticipated consequences

Difficulty regulating anxiety

Many people with anxiety have difficulty regulating their emotions

It can be difficult for someone who is experiencing anxiety to feel calm
Feelings of anxiety may be transferred from the real world to the fictional world of the film. Here, the events that lead to anxiety do not actually affect the viewer.

Viewers can regulate the intensity of anxiety by covering their eyes, turning on the lights, turning down the sound, or watching with a friend.

People can experience a "comedown" effect that boosts mood and relaxation after finishing a horror movie, similar to what happens after exercising or experiencing something thrilling.

\section{Leveraging Horror Content as an Experiential Tool for Learning}

\section{Learning from Scary Play}

An important next step is to examine whether engagement with recreational horror can be used to generate resilience and better adaptation in real-world situations by offering an entertaining inroad to engaging with negative affect and anxietyprovoking stimuli. An analogy may be made with rough-and-tumble play. Most juvenile mammals engage in some sort of rough-and-tumble play (Boulton \& Smith, 1992). For example, small children may engage in chase play such as hide-and-seek or tag, games that seem benign but represent potentially scary predation situations. Roughand-tumble play in humans and other animals often mimics dangerous real-world situations, such as violent altercations, without the risk of injury. In this way, rough-andtumble play can allow juveniles to learn behavioral strategies and motor skills involved in similar situations outside of the playful environment (Kniffin \& Scalise-Sugiyama, 2018; Scalise-Sugiyama et al., 2018; Steen \& Owens, 2001).

Like rough-and-tumble play, horror fiction provides a simulation in which people can engage with frightening phenomena in a safe setting. The ability to gather information through fiction or imagination is even more beneficial when the situation being simulated is dangerous. It is costly to interact with dangerous situations in the real world, yet it is also important to learn about dangerous phenomena so that they can be effectively dealt with when they are encountered. In the cognitive playground of a fictional world, people can learn what a particular situation looks like and engage in emotional and behavioral strategies that could prepare for related situations in the real 
world (Morin et al., 2019; Scalise-Sugiyama, 2001). Supporting this hypothesis, Scrivner et al. (2021) found that horror fans experienced less psychological distress during the COVID-19 pandemic than non-horror fans. Specifically, horror fans reported less anxiety, depression, irritability, and sleeplessness in the early months of the pandemic. Streaming service NOW TV also conducted a survey of its users showing that a significant number of people were streaming apocalyptic movies during the pandemic in order to feel better about the current state of the world. Similar to findings by Scrivner et al. (2021), NOW TV users who were fans of apocalyptic genres reported feeling more prepared for a second wave of COVID (Gifford, 2020). In the next sections, we propose ideas for incorporating horror media as an experiential tool in conjunction with empirically validated treatments for anxiety-related disorders.

\section{Building on processes from cognitive behavioral therapy and exposure therapy}

The proposition that engagement with horror content could provide skills that allow one to feel a greater mastery over certain anxiety-provoking situations and reduce general distress suggests a potential utility for incorporating horror content into therapeutic contexts. There are multiple empirically validated psychological treatments that have been developed for internalizing disorders in which clients directly confront or challenge the experience of anxiety to reduce the onset or intensity of the emotion and subsequent problematic behaviors. Although clinicians may already use aspects of horror films to treat problems related to anxiety (e.g., showing film clips as part of an exposure hierarchy to treat specific phobias or obsessive thoughts), the formalized use of horror content as a therapeutic tool is a relatively novel idea and is grounded within existing theories underlying cognitive-behavioral treatments (CBT) and exposure therapy ${ }^{1}$.

In cognitive-behavioral treatments (CBT), individuals are taught to recognize the relationships between their thoughts, emotions, and behaviors and learn skills to modify problematic patterns of thinking (Beck et al., 1979). Typically, this includes an assessment of the realistic threat posed by a stimulus and the client's perceived abilities to cope. In CBT, clients are taught skills to break maladaptive associations between thoughts, emotions, and behaviors and to instead use more adaptive and effective

\footnotetext{
${ }^{1}$ We frame the discussion of the use of horror content within the context of evidence-based therapies that are recommended by the American Psychological Association for anxiety disorders, obsessivecompulsive disorder, mood disorders, post-traumatic stress disorder, and eating disorders (APA Presidential Task Force on Evidence-Based Practice, 2006). However, it should be noted that there are numerous theoretical formulations of horror content as a tool for processing trauma and anxiety within the humanities literatures (e.g., media studies, gender studies, queer studies) that are rooted in psychoanalytic or psychodynamic perspectives (e.g.. Badley, 1995; Grant, 2015; Lennard, 2014; Schneider, 2004). Such formulations explore horror as a space for subversion and exploration of sociocultural anxieties, including but not limited to, concerns about gender, sexuality, motherhood, race, identity, and conflicts between inner self and outer roles. We encourage the interested reader to explore this rich interdisciplinary literature, which is outside the scope of the present manuscript.
} 
strategies to manage distress. In exposure therapy, which may be applied in vivo or imaginally, clients expose themselves to anxiety- or fear-provoking situations (e.g., Abramowitz, Deacon, \& Whiteside, 2019), with the goal of reducing future avoidance of these stimuli. Exposure therapy may be combined with response prevention techniques, for example when treating obsessive-compulsive disorders (see meta-analysis in RosaAlcazar et al., 2008) or eating disorders (see review in Koskina, Campbell, \& Schmidt, 2013), to eliminate the use of safety behaviors that maintain maladaptive patterns. Exposure therapy is the recommended treatment by the American Psychological Association (APA Presidential Task Force on Evidence-Based Practice, 2006) for specific phobia, agoraphobia, panic disorder, obsessive-compulsive and related disorders, and post-traumatic stress disorder (i.e., Prolonged Exposure Therapy) and exposure techniques are frequently incorporated in the treatment for generalized anxiety disorder (e.g., worry exposures, Hoyer \& Beesdo-Baum, 2012), eating disorders (e.g., mirror or food exposures, Becker, Farrell, \& Waller, 2019), and social anxiety disorder (e.g., public speaking exposures; Acaturk, van Straten, \& de Graaf, 2008).

In the following sections, we describe potential theories linking underlying theories of CBT and exposure therapy to learning processes during the use of horror content, as well as provide suggestions for how horror content could be incorporated into clinical practice. We propose that horror media may offer an entertaining, engaging, and attractive tool for clients to practice core cognitive-behavioral and exposure constructs, particularly for those who already use this content. First, many people are familiar with and enjoy engaging with horror media. Horror content is popular; in 2019, horror movies grossed approximately $\$ 787$ million dollars at the box office (The Numbers, 2019). Second, it is possible that for some clients engaging with horror content may lower barriers towards treatment. For example, men, who frequently report viewing and enjoying horror content (Martin, 2019), tend to have lower rates of treatment-seeking for psychological issues, in part because they not may perceive current therapeutic options as meeting their needs (Liddon, Kingerlee, \& Barry, 2018) or feel a need for independence and emotional control (Yousaf et al., 2013). Thus, approaches using experiential tools that appeal to this demographic (although, not limited to), who already engage with this content may be of particular interest.

\section{Engagement with fictional horror could increase emotional clarity}

Many people with elevated anxiety exhibit difficulties in identifying their emotions (e.g., Vine \& Aldao, 2014), a construct known as emotional clarity (Salovey et al., 1995). Low emotional clarity may manifest itself through two different facets: poor source awareness (i.e., difficulty in identifying the source of an emotion) and/or as poor type awareness (i.e., difficulty in identifying or distinguishing between specific emotions) (Boden \& Berenbaum, 2011). Emotional clarity is negatively associated with well-being (Gohm \& Clore, 2010) and symptoms of anhedonic depression, social anxiety, 
borderline personality, binge eating, and alcohol use (Vine \& Aldao, 2014). Furthermore, lower levels of emotional clarity have been found in those with diagnoses of major depressive disorder and social anxiety disorder compared to controls (Thompson, Boden, \& Gotlib, 2015). Additionally, there is evidence to suggest that emotional clarity predicts longitudinal outcomes such as depression and well-being (Haas et al., 2019). Consequently, multiple therapeutic interventions, such as the Unified Protocol for Transdiagnostic Treatment of Emotional Disorders (Barlow et al., 2010), Dialectical Behavior Therapy (Linehan, 1993), and Emotion Regulation Therapy (Fresco et al., 2013) focus on increasing emotional awareness and recognition to help facilitate better outcomes. Within these modalities, emotional awareness training exercises, such as mindfulness (see meta-analysis in Cooper, Yap, \& Batalha, 2018) are typically used. To our knowledge, there has yet to be a study that has evaluated if individuals can improve emotional clarity through guided instruction using film clips, such as horror films, although using horror to process clinical trauma has been reported in one case study (Turley \& Derdeyn, 1990) and proposed as a possible therapeutic technique (Hamilton \& Sullivan, 2015; Hamilton, 2020).

We suggest that horror content has potential as a therapeutic tool to provide psychoeducation about the nature of anxiety and fear and a learning tool for increasing emotional clarity (source and type awareness). First, horror content is designed to evoke high levels of anxiety (through the use of music, lighting, plot, etc.) as well as acute moments of fear (through exposure to stimuli such as sudden sounds, monsters, gore, etc.), which allows a reliable evocation of these responses to allow for source awareness. We propose that horror content contains emotional archetypes of anxiety and fear that allow for easy identification (type awareness), which, with practice, could be generalized to increase identification of emotions generated by non-horror stimuli.

Emotional evocation in horror may exist in specific forms (e.g., stimuli such as home invasions, insects, or blood) of varying levels of personal relevance to the client, or could be a generalized tool to elicit elevated affect (e.g., elements of suspense). Therapists who use either CBT or EXP orientations could assign viewing content as homework assignments to help clients to learn how to clearly identify the thoughts and physiological sensations that go along with the emotions of anxiety and fear. There are already databases and books available with ratings that identify horror content of varying intensities and types (e.g., Glasby, 2020, Schaerfer et al., 2010). Furthermore, finding and accessing specific content is made easy through popular websites such as "Where's the Jump?" (https://www.wheresthejump.com) and "Does the Dog Die?" (https://www.doesthedogdie.com), which are frequently updated with categories and time points of emotionally evocative scenes and stimuli found in television and movies. Overall, horror content is a readily accessible tool for the clinician, with resources already in place to help therapists and clients identify evocative, highly salient stimuli for generating anxiety responses. 


\section{Using horror as a "behavioral experiment"}

Horror content holds numerous opportunities for clients to expose themselves to a variety of anxiety-provoking stimuli, as in the case of exposure therapy. For the purposes of this discussion, we focus on cognitive processes associated with exposure ${ }^{2}$, specifically the notion that exposure provides the opportunity for clients to learn that their experience of anxiety does not always match the actual threat posed by a stimulus and that they can tolerate or manage their emotions (e.g., Clark, 1999). Thus, the primary goal of this type of exposure is not to habituate to the stimuli, although between- and within-session habituation is likely to occur with repeated exposures (Maples-Keller \& Rauch, 2020); instead, the goal is to test the plausibility of the cognitions about the stimulus. Exposure to horror content may provide people with elevated anxiety a safe space to practice multiple types of "behavioral experiments" in which they test the validity of their worries and practice strategies to manage their emotional experiences. This includes examining emotional intensity as a predictor of threat, testing the validity of thoughts about the meaning of physiological symptoms, learning new strategies to regulate emotions, and practicing coping ahead.

\section{Challenging emotional reasoning}

Exposing oneself to elevated anxiety and systematically evaluating the intensity of the emotion against the threat posed is an important area of exploration for people with anxiety symptoms. Many people with anxiety endorse the use of emotional reasoning (also known as the "mistaking feelings for facts" cognitive distortion), in which they believe that the intensity of the emotion experienced is a valid indicator of the threat posed by a stimulus (Berle \& Moulds, 2013). This distortion can be easily challenged with exposure to horror media, as clients may experience high levels of anxiety in response to actions on-screen, while in reality, they are at no risk of harm. In this way, clients can learn that the intensity of their emotions is not always a reliable indicator of the threat posed by a situation and can practice not responding to elevated emotions (e.g., with avoidance).

To put this into practice, therapists could design exercises in which clients view horror media and record their thoughts, emotions, and behaviors. Clients and therapists may then review these logs in order to systematically challenge the reality of the danger posed by the exposure in relation to the intensity of the emotional experience and thought content. This exercise has the potential to illustrate to clients that the emotional and physiological experience of anxiety does not have to map onto the actual danger posed by a situation. The therapist could then work with the client to design additional

\footnotetext{
${ }^{2}$ Although outside the scope of this paper, numerous other theories (such as habituation theory) have been developed to explain why exposure therapy is effective, with varying degrees of support (see chapter in Telch, Cobb, \& Lancaster, 2014).
} 
homework exercises in which the client practices identifying emotional reasoning and challenging it using horror media, with the intention of generalizing this skill to nonhorror contexts in which emotional reasoning occurs.

\section{Learning to tolerate somatic experiences}

Another potential application of horror content is to offer people with elevated anxiety the opportunity to learn how to tolerate the physical experience of feeling anxious. Many people with anxiety have catastrophic misinterpretations associated with somatic experiences of anxiety and/or habitually avoid these physical sensations (i.e., experiential avoidance; Hayes et al., 2004). Experiential avoidance, which has been conceptualized as a transdiagnostic construct, is problematic as it tends to impair quality of life and functioning (e.g., Boulanger, Hayes, \& Pistorello, 2010).The debilitating effects of experiential avoidance are clearly illustrated when considering the diagnosis of agoraphobia, in which people purposely avoid situations due to a concern that one might experience somatic symptoms associated with panic attacks and be unable to escape or receive help (American Psychiatric Association, 2013). Repeated exposure to the experience of anxiety through horror content may offer individuals who engage in experiential avoidance the opportunity to disconfirm catastrophic beliefs about what it means to experience these symptoms (e.g., an elevated heart rate does not necessarily signal the onset of a panic attack). Furthermore, horror exposures offer clients the opportunity to "ride the wave" and establish that negative emotions are tolerable, brief, and do not last forever.

Horror media could be systematically incorporated into exercises found in Acceptance and Commitment Therapy, in which clients practice experiencing these high levels of emotions without judgment or reaction (Hayes, Strosahl, \& Wilson, 1999). For example, clients could view horror media while allowing themselves to fully and nonjudgmentally experience the emotions and somatic symptoms ("ride the wave"), without attempting to modify them. Another potential application can be found in the emotional exposures module of the Unified Protocol for Transdiagnostic Treatment of Emotional Disorders (Barlow et al., 2010). In this exercise, clients could complete "emotional exposures" by using horror media to identify and challenge negative cognitions about experiencing high levels of somatic symptoms and evaluate the validity of concerns about potential catastrophic outcomes.

\section{Practicing cognitive reappraisal}

Horror content also offers clients many opportunities to practice "training" with cognitive skills to cope with anxiety- or fear-producing content. For instance, when viewing a horror film, individuals may practice cognitive reappraisal, a common emotion regulation skill in which people change their thinking in order to alter their emotions (Andrade \& Cohen, 2008; Clasen et al., 2019). In general, people who use cognitive 
reappraisal more frequently tend to report lower levels of psychopathology (Aldao et al., 2010), leading many to characterize cognitive reappraisal as an adaptive emotion regulation mechanism. Cognitive reappraisal is a core component of cognitive-behavior therapy (e.g., Beck et al., 1979), as clients are taught to evaluate the veracity of their thoughts and how their thoughts influence behaviors and emotions. Horror films offer numerous opportunities for reappraising thoughts related to anxiety-provoking stimuli and emotional responses. When viewing horror, people may engage in multiple types of reappraisal; for example, they may choose to reappraise the stimulus (e.g., "This is a horror film and the actors are not in actual danger") or they may reappraise their emotional experience (e.g., "My anxiety is temporary and will soon pass"). On average, reappraising stimuli tends to show greater effects in reducing negative affect (see metaanalysis by Webb et al., 2012), increasing positive affect when viewing horror films (Andrade \& Cohen, 2008), and is associated with greater behavioral approach (e.g., Wilson, Aldao, \& Cheavens, 2018), suggesting that it may be an effective skill. Horror content offers the client opportunities to practice with both types of reappraisal and learn how to effectively apply this skill.

Previous studies have investigated the use of cognitive reappraisal training and found evidence for reductions in negative affect, although the interventions primarily consisted of brief trainings using aversive images (e.g., Denny \& Ochsner, 2014; Shore et al., 2017). There has yet to be a formal test of how horror films could be used as training tools for learning and practicing cognitive reappraisal. We propose that practicing cognitive reappraisal skills in the context of horror films is highly promising in that it offers a "less risky" context, as the client is viewing media that do not pose a direct, personal threat (i.e., greater psychological and emotional distance) to learn skills that can be generalized later to other, more personally salient stimuli. In this manner, clients and therapists could work together to generate heightened easily identifiable emotions and then practice identifying emotions, physical sensations, behaviors, and thoughts. Maladaptive thoughts could then be evaluated and restructured using cognitive reappraisal. As the client becomes more skilled at performing reappraisal, the therapist and client could apply this skill to other emotion-eliciting situations that may have greater personal salience.

Table 2. Potential Methods for Leveraging Horror Media in Evidence-Based Therapies.

Therapeutic Construct

Explanation

People with anxiety may

Increasing Emotional

Clarity have difficulties identifying

the source and nature of their emotions.
How to Incorporate Horror

Therapists can use horror media as a training tool for clients to identify the physiological, behavioral, and emotional correlates of anxiety. 


\begin{tabular}{|c|c|c|}
\hline $\begin{array}{l}\text { Challenging emotional } \\
\text { reasoning }\end{array}$ & $\begin{array}{l}\text { In this thought distortion, } \\
\text { emotional intensity is taken } \\
\text { as evidence of the threat } \\
\text { posed by a stimulus. }\end{array}$ & $\begin{array}{l}\text { Therapists and clients can record } \\
\text { thoughts, emotions, and behaviors } \\
\text { associated with viewing horror media } \\
\text { and analyze these logs to challenge } \\
\text { maladaptive thinking. }\end{array}$ \\
\hline $\begin{array}{l}\text { Tolerating Somatic } \\
\text { Experiences }\end{array}$ & $\begin{array}{l}\text { Many people with anxiety } \\
\text { chose to avoid } \\
\text { uncomfortable somatic } \\
\text { sensations. }\end{array}$ & $\begin{array}{l}\text { Horror media elicits heightened } \\
\text { physiological responses. Through } \\
\text { repeated exposure, clients can } \\
\text { disconfirm catastrophic beliefs about } \\
\text { experiencing somatic symptoms and } \\
\text { learn to tolerate uncomfortable physical } \\
\text { sensations without overreacting. }\end{array}$ \\
\hline $\begin{array}{l}\text { Practicing Cognitive } \\
\text { Reappraisal }\end{array}$ & $\begin{array}{l}\text { People with anxiety may } \\
\text { have a bias towards } \\
\text { negative interpretations of } \\
\text { situations and benefit from } \\
\text { reappraising their thoughts. }\end{array}$ & $\begin{array}{l}\text { Horror media offers a low-risk } \\
\text { opportunity to learn how to generate } \\
\text { cognitive reappraisals related to negative } \\
\text { stimuli and emotional experiences. Once } \\
\text { strengthened, this skill could be applied } \\
\text { to other emotion-eliciting situations. }\end{array}$ \\
\hline
\end{tabular}

\section{Summary and Conclusions}

\section{Using horror fiction to help with anxiety in the moment}

One of the main goals of this paper was to explain why people with anxiety symptoms may seek out horror content and to identify possible mechanisms by which horror movies may reduce acute anxiety. Though seemingly paradoxical, there are several explanations for why people with anxiety sometimes seek out anxiety-inducing movies. Horror plots may be inherently alluring to someone who is high in anxiety. This may be especially true for those who exhibit contrast avoidance, as horror could be one way to maintain elevated negative emotions. Threat-related attention biases are also exaggerated among populations with clinical and subclinical anxiety. Typically, the central figure or theme in a horror film is some type of threat - a psychopathic killer, monster, or other dangerous figure. Thus, the prominence of threat to horror films serves as an attentional attractor, particularly among people with anxiety. In the same way that anxiety may lead someone to fixate on a real-world threat, it can more easily immerse them into the threat-focused plot of a horror film. 
Once tuned into the plot, people with anxiety may feel free to express the emotions that they are experiencing. When watching a horror film, it is expected that viewers express feelings of anxiety and fear. This can come as a relief to anxious individuals who believe that they need to hide how they are feeling. Additionally, the horror films may take over as the source of anxiety for the viewer. This shift in the source of anxiety serves two purposes. First, it can provide clarity for the anxious viewer by offering an identifiable source of anxiety. Second, it allows the anxious viewer to take control of their anxiety and regulate it in a variety of ways that are ineffective when the anxiety is not rooted in a movie. Finally, anxious viewers can experience a sense of relief when the film ends. This may be emotional relief when the story resolves and the threat is no longer present, but it can also be a neurobiologically-based euphoria that stems from the release of endocannabinoids and endorphins after a stressful experience.

Taken together, these factors may explain why anxious people sometimes consume horror films and how this experience may alleviate their anxiety. Thus, horror may serve as a sort of low-risk and low-cost method for some people with anxiety. This raises the question of whether or not these experiences could also provide some sort of long-term benefit beyond temporary relief. Although this could be a promising technique for increasing resilience, it is critical to consider and evaluate if horror media may function as a safety behavior and contribute to the maintenance of anxiety pathology. For example, if people use horror media to avoid other anxiety-eliciting stimuli, to avoid emotional contrast, or to reduce anxiety in the moment, then this may inhibit them from appropriate engagement and opportunities for disconfirming negative beliefs. Thus, future research should evaluate the function of horror media and the extent to which it facilitates short-term goals (e.g., reducing anxiety) and long-term adaptation.

\section{Using horror fiction to build more generalized resilience}

Another main goal of this paper was to identify how horror content could be leveraged for use in empirically validated treatments for internalizing disorders. We argue that horror content is ideally suited for "practice" material for clients who would benefit from developing a more adaptive relationship with the experience of anxiety and learning how to challenge maladaptive thoughts. Horror media is designed to be entertaining, engaging, and emotionally evocative and consequently, clients may view such homework assignments as enjoyable and approachable. Furthermore, horror content offers a strong training ground with easily identifiable emotional content and sources that allow the client to learn how to approach and tolerate negative affect. It also provides a less-threatening context for clients to learn skills to evaluate the validity of thoughts, cognitively restructure, and consider how they would cope ahead for realistic worries. 
Next steps for research in this area would be to evaluate how effectively horror content serves these goals. This would involve systematically testing the feasibility (e.g., client satisfaction, engagement) and effectiveness (e.g., changes in emotional, physiological, and behavioral outcomes) of using horror media within the structure of cognitive-behavioral or exposure interventions. Analogue studies could be used to examine evidence for mechanisms of change (e.g., if horror media can be used to increase emotional clarity), with extension to clinical populations to test treatment effects. This could be accomplished through the use of single-case experimental designs (e.g., multiple-baseline designs), and if preliminary efficacy is established, randomized controlled trials in which clients are randomized to receive horror-based techniques within their treatment or treatment as usual.

\section{Conclusions}

We have presented a theoretical rationale for the incorporation of recreational horror in the treatment of anxiety symptoms. Many questions remain about the possible therapeutic use of horror. Future research should identify cognitive and emotional processes during scary fictional experiences and the short and long-term consequences of using horror media. It may also be of use to understand if there are certain populations of people who would benefit from these tools (e.g., people who experience barriers to engaging with traditional therapeutic contexts) and if it increases engagement in therapy and reduces drop-out. In sum, we believe that horror fiction provides a largely untapped clinical resource for anxiety-related disorders and have outlined possible mechanisms through which horror may serve adaptive and maladaptive roles in influencing short-term anxiety symptoms and could be appropriately leveraged to teach adaptive psychological skills.

\section{References}

Abramowitz, J. S., Deacon, B. J., \& Whiteside, S. P. H. (2019). Exposure Therapy for Anxiety, Second Edition: Principles and Practice. Guilford Publications.

Acarturk, C., de Graaf, R., van Straten, A., Have, M. T., \& Cuijpers, P. (2008). Social phobia and number of social fears, and their association with comorbidity, healthrelated quality of life and help seeking: A population-based study. Social 
Psychiatry and Psychiatric Epidemiology, 43(4), 273-279. https://doi.org/10.1007/s00127-008-0309-1

Aldao, A., \& Christensen, K. (2015). Linking the expanded process model of emotion regulation to psychopathology by focusing on behavioral outcomes of regulation. Psychological Inquiry, 26(1), 27-36.

https://doi.org/10.1080/1047840X.2015.962399

Aldao, A., Nolen-Hoeksema, S., \& Schweizer, S. (2010). Emotion-regulation strategies across psychopathology: A meta-analytic review. Clinical Psychology Review, 30(2), 217-237. https://doi.org/10.1016/j.cpr.2009.11.004

American Psychiatric Association. (2013). Diagnostic and statistical manual of mental disorders (5th ed.). American Psychiatric Publishing.

Andrade, E. B., \& Cohen, J. B. (2007). On the Consumption of Negative Feelings. Journal of Consumer Research, 34(3), 283-300. https://doi.org/10.1086/519498

Andersen, M. M., Schjoedt, U., Price, H., Rosas, F. E., Scrivner, C., \& Clasen, M. (2020). Playing with fear: a field study in recreational horror. Psychological science, 31(12), 1497-1510. https://doi.org/10.1177\%2F0956797620972116

Ansani, A., Marini, M., D’Errico, F., \& Poggi, I. (2020). How Soundtracks Shape What We See: Analyzing the Influence of Music on Visual Scenes Through SelfAssessment, Eye Tracking, and Pupillometry. Frontiers in Psychology, 11. https://doi.org/10.3389/fpsyg.2020.02242

APA Presidential Task Force on Evidence-Based Practice. (2006). Evidence-based practice in psychology. American Psychologist, 61, 271-285.

Aristotle. (1997). Poetics (M. Heath, Trans.; New Ed edition). Penguin Classics. 
Ashwin, C., Holas, P., Broadhurst, S., Kokoszka, A., Georgiou, G. A., \& Fox, E. (2012). Enhanced anger superiority effect in generalized anxiety disorder and panic disorder. Journal of Anxiety Disorders, 26(2), 329-336. https://doi.org/10.1016/j.janxdis.2011.11.010

Asma, S. T. (2009). On Monsters: An Unnatural History of Our Worst Fears. Oxford University Press.

Badley, L. (1995). Film, Horror, and the Body Fantastic. Greenwood Publishing Group.

Barber, E. J. W., \& Barber, P. (2004). When They Severed Earth from Sky: How the Human Mind Shapes Myth. Princeton University Press.

Bar-Haim, Y., Lamy, D., Pergamin, L., Bakermans-Kranenburg, M. J., \& van IJzendoorn, M. H. (2007). Threat-related attentional bias in anxious and nonanxious individuals: A meta-analytic study. Psychological Bulletin, 133(1), 124. https://doi.org/10.1037/0033-2909.133.1.1

Barlow, D. H., Farchione, T. J., Fairholme, C. P., \& Ellard, K. K. (2010). Unified Protocol for Transdiagnostic Treatment of Emotional Disorders: Therapist Guide. Oxford University Press, USA.

Barrett, H. C. (2015). Adaptations to Predators and Prey. In The Handbook of Evolutionary Psychology (pp. 1-18). American Cancer Society. https://doi.org/10.1002/9781119125563.evpsych109

Bateson, M., Brilot, B., \& Nettle, D. (2011). Anxiety: An Evolutionary Approach. The Canadian Journal of Psychiatry, 56(12), 707-715. https://doi.org/10.1177/070674371105601202 
Beck, A. T. (1979). Cognitive Therapy of Depression. Guilford Press.

Becker, C. B., Farrell, N. R., \& Waller, G. (2019). Exposure Therapy for Eating Disorders. Oxford University Press.

Beesdo-Baum, K., Jenjahn, E., Höfler, M., Lueken, U., Becker, E. S., \& Hoyer, J. (2012). Avoidance, Safety Behavior, and Reassurance Seeking in Generalized Anxiety Disorder. Depression and Anxiety, 29(11), 948-957. https://doi.org/10.1002/da.21955

Bellet, B. W., Jones, P. J., \& McNally, R. J. (2020). Self-triggering? An exploration of individuals who seek reminders of trauma. Clinical Psychological Science, 8(4), 739-755. https://doi.org/10.1177/2167702620917459

Berle, D., \& Moulds, M. L. (2013). Emotional Reasoning Processes and Dysphoric Mood: Cross-Sectional and Prospective Relationships. PLOS ONE, 8(6), e67359. https://doi.org/10.1371/journal.pone.0067359

Blaine, T., \& Boyer, P. (2018). Origins of sinister rumors: A preference for threat-related material in the supply and demand of information. Evolution and Human Behavior, 39(1), 67-75. https://doi.org/10.1016/j.evolhumbehav.2017.10.001

Blanchard, D. C., Griebel, G., Pobbe, R., \& Blanchard, R. J. (2011). Risk assessment as an evolved threat detection and analysis process. Neuroscience and Biobehavioral Reviews, 35(4), 991-998. https://doi.org/10.1016/j.neubiorev.2010.10.016

Boden, M. T., \& Berenbaum, H. (2011). What you are feeling and why: Two distinct types of emotional clarity. Personality and Individual Differences, 51(5), 652-656. https://doi.org/10.1016/j.paid.2011.06.009 
Bouchard, S., St-Jacques, J., Robillard, G., \& Renaud, P. (2008). Anxiety increases the feeling of presence in virtual reality. Presence: Teleoperators and Virtual Environments, 17(4), 376-391. https://doi.org/10.1162/pres.17.4.376

Boulanger, J. L., Hayes, S. C., \& Pistorello, J. (2010). Experiential avoidance as a functional contextual concept. In Emotion regulation and psychopathology: A transdiagnostic approach to etiology and treatment (pp. 107-136). The Guilford Press.

Boulton, M. J., \& Smith, P. K. (1992). The social nature of play fighting and play chasing: Mechanisms and strategies underlying cooperation and compromise. In The adapted mind: Evolutionary psychology and the generation of culture (pp. 429-444). Oxford University Press.

Bouton, M. E., Mineka, S., \& Barlow, D. H. (2001). A modern learning theory perspective on the etiology of panic disorder. Psychological Review, 108(1), 432. https://doi.org/10.1037/0033-295X.108.1.4

Brown, M., Robinson, L., Campione, G. C., Wuensch, K., Hildebrandt, T., \& Micali, N. (2017). Intolerance of Uncertainty in Eating Disorders: A Systematic Review and Meta-Analysis. European Eating Disorders Review: The Journal of the Eating Disorders Association, 25(5), 329-343. https://doi.org/10.1002/erv.2523

Butler, E. A., Egloff, B., Wilhelm, F. H., Smith, N. C., Erickson, E. A., \& Gross, J. J. (2003). The social consequences of expressive suppression. Emotion (Washington, D.C.), 3(1), 48-67. https://doi.org/10.1037/1528-3542.3.1.48

Campbell-Sills, L., Barlow, D. H., Brown, T. A., \& Hofmann, S. G. (2006). Effects of suppression and acceptance on emotional responses of individuals with anxiety 
and mood disorders. Behaviour Research and Therapy, 44(9), 1251-1263. https://doi.org/10.1016/j.brat.2005.10.001

Cantor, J., \& Sparks, G. G. (1984). Children's fear responses to mass media: Testing some piagetian predictions. Journal of Communication, 34(2), 90-103. https://doi.org/10.1111/j.1460-2466.1984.tb02162.x

Carroll, N. (1990). The philosophy of horror: Or, paradoxes of the heart. Routledge.

Christensen, K., \& Aldao, A. (2015). Tipping points for adaptation: Connecting emotion regulation, motivated behavior, and psychopathology. Current Opinion in Psychology, 3, 70-74. https://doi.org/10.1016/j.copsyc.2014.12.015

Cisler, J. M., Bacon, A. K., \& Williams, N. L. (2009). Phenomenological characteristics of attentional biases towards threat: A critical review. Cognitive Therapy and Research, 33(2), 221-234. https://doi.org/10.1007/s10608-007-9161-y

Clark, D. M. (1999). Anxiety disorders: Why they persist and how to treat them. Behaviour Research and Therapy, 37 Suppl 1, S5-27. https://doi.org/10.1016/s0005-7967(99)00048-0

Clasen, M. (2017). Why horror seduces (1st edition). Oxford University Press.

Clasen, M., Andersen, M., \& Schjoedt, U. (2019). Adrenaline junkies and whiteknucklers: A quantitative study of fear management in haunted house visitors. Poetics, 73, 61-71. https://doi.org/10.1016/j.poetic.2019.01.002

Clasen, M., Kjeldgaard-Christiansen, J., \& Johnson, J. A. (2020). Horror, personality, and threat simulation: A survey on the psychology of scary media. Evolutionary Behavioral Sciences, 14(3), 213-230. https://doi.org/10.1037/ebs0000152 
Cooper, D., Yap, K., \& Batalha, L. (2018). Mindfulness-based interventions and their effects on emotional clarity: A systematic review and meta-analysis. Journal of Affective Disorders, 235, 265-276. https://doi.org/10.1016/j.jad.2018.04.018

Curcio, C., \& Corboy, D. (2020). Stigma and anxiety disorders: A systematic review. Stigma and Health, 5(2), 125-137. https://doi.org/10.1037/sah0000183

Davis, H., \& McLeod, S. L. (2003). Why humans value sensational news: An evolutionary perspective. Evolution and Human Behavior, 24(3), 208-216. https://doi.org/10.1016/S1090-5138(03)00012-6

Denny, B. T., \& Ochsner, K. N. (2014). Behavioral effects of longitudinal training in cognitive reappraisal. Emotion (Washington, D.C.), 14(2), 425-433. https://doi.org/10.1037/a0035276

Does The Dog Die? (n.d.). Retrieved February 3, 2021, from https://www.doesthedogdie.com/

Dugas, M. J., Freeston, M. H., \& Ladouceur, R. (1997). Intolerance of uncertainty and problem orientation in worry. Cognitive Therapy and Research, 21(6), 593-606. https://doi.org/10.1023/A:1021890322153

Einstein, D. A. (2014). Extension of the Transdiagnostic Model to Focus on Intolerance of Uncertainty: A Review of the Literature and Implications for Treatment. Clinical Psychology: Science and Practice, 21(3), 280-300. https://doi.org/10.1111/cpsp.12077

English, T., \& John, O. P. (2013). Understanding the social effects of emotion regulation: The mediating role of authenticity for individual differences in 
suppression. Emotion (Washington, D.C.), 13(2), 314-329. https://doi.org/10.1037/a0029847

Felton, D. (2010). Haunted Greece and Rome: Ghost Stories from Classical Antiquity. University of Texas Press.

Fresco, D. M., Mennin, D. S., Heimberg, R. G., \& Ritter, M. (2013). Emotion Regulation Therapy for Generalized Anxiety Disorder. Cognitive and Behavioral Practice, 20(3), 282-300. https://doi.org/10.1016/..cbpra.2013.02.001

Gaut, B. (1993). The paradox of horror. The British Journal of Aesthetics, 33(4), 333345. https://doi.org/10.1093/bjaesthetics/33.4.333

Gentes, E. L., \& Ruscio, A. M. (2011). A meta-analysis of the relation of intolerance of uncertainty to symptoms of generalized anxiety disorder, major depressive disorder, and obsessive-compulsive disorder. Clinical Psychology Review, 31(6), 923-933. https://doi.org/10.1016/j.cpr.2011.05.001

Gifford, B. (2020, September 24). The psychology behind watching apocalypse films during a pandemic. Happiful Magazine. https://happiful.com/psychologywatching-post-apocalyptic-films-during-pandemic

Glasby, M. (2020a). The Book of horror: The anatomy of fear in film. Quarto Publishing Group UK.

Glasby, M. (2020b). The Book of Horror: The Anatomy of Fear in Film. Quarto Publishing Group UK.

Gohm, C. L., \& Clore, G. L. (2002). Four latent traits of emotional experience and their involvement in well-being, coping, and attributional style. Cognition and Emotion, 16(4), 495-518. https://doi.org/10.1080/02699930143000374 
Grisafi, P. (2016, January 20). How horror movies help me cope with anxiety. Luna Luna. http://www.lunalunamagazine.com/blog/how-horror-movies-help-me-copewith-anxiety

Gross, J. J. (1998). Antecedent- and response-focused emotion regulation: Divergent consequences for experience, expression, and physiology. Journal of Personality and Social Psychology, 74(1), 224-237. https://doi.org/10.1037//0022$\underline{3514.74 .1 .224}$

Gross, James J., \& John, O. P. (2003). Individual differences in two emotion regulation processes: Implications for affect, relationships, and well-being. Journal of Personality and Social Psychology, 85(2), 348-362. https://doi.org/10.1037/0022-

\section{$\underline{3514.85 .2 .348}$}

Gutiérrez-García, A., \& Contreras, C. (2013). Anxiety: An Adaptive Emotion. In F. Durbano (Ed.), New Insights into Anxiety Disorders (pp. 21-37). InTech.

Haas, L. M., McArthur, B. A., Burke, T. A., Olino, T. M., Abramson, L. Y., \& Alloy, L. B. (2019). Emotional ClarityDevelopment and Psychosocial Outcomes During Adolescence. Emotion (Washington, D.C.), 19(4), 563-572. https://doi.org/10.1037/emo0000452

Hamilton, J. (2020). Monsters and posttraumatic stress: An experiential-processing model of monster imagery in psychological therapy, film and television. Humanities and Social Sciences Communications, 7(1), 1-8. https://doi.org/10.1057/s41599-020-00628-2 
Hamilton, J., \& Sullivan, J. (2015). Horror in Therapy: Working Creatively with Horror and Science Fiction Films in Trauma Therapy. CreateSpace Independent Publishing Platform.

Hansen, C. H., \& Hansen, R. D. (1988). Finding the face in the crowd: An anger superiority effect. Journal of Personality and Social Psychology, 54(6), 917-924. https://doi.org/10.1037/0022-3514.54.6.917

Hayes, S. C., Strosahl, K. D., \& Wilson, K. G. (1999). Acceptance and commitment therapy: An experiential approach to behavior change (Vol. xvi). Guilford Press.

Hayes, S. C., Strosahl, K., Wilson, K. G., Bissett, R. T., Pistorello, J., Toarmino, D., Polusny, M. A., Dykstra, T. A., Batten, S. V., Bergan, J., Stewart, S. H., Zvolensky, M. J., Eifert, G. H., Bond, F. W., Forsyth, J. P., Karekla, M., \& McCurry, S. M. (2004). Measuring experiential avoidance: A preliminary test of a working model. The Psychological Record, 54(4), 553-578. https://doi.org/10.1007/BF03395492

Hoffner, C. A., \& Levine, K. J. (2005). Enjoyment of mediated fright and violence: A meta-analysis. Media Psychology, 7(2), 207-237. https://doi.org/10.1207/S1532785XMEP0702 5

Hofmann, S. G., \& Hay, A. C. (2018). Rethinking avoidance: Toward a balanced approach to avoidance in treating anxiety disorders. Journal of Anxiety Disorders, 55, 14-21. https://doi.org/10.1016/j.janxdis.2018.03.004

Hume, D. (2008). Of tragedy. In S. Copley \& A. Edgar (Eds.), Selected essays (1st edition). Oxford University Press. 
Kensinger, E. A. (2007). Negative emotion enhances memory accuracy: Behavioral and neuroimaging evidence. Current Directions in Psychological Science, 16(4), 213218. https://doi.org/10.1111/j.1467-8721.2007.00506.x

King, S. (2010). Danse macabre (Reprint edition). Gallery Books.

Kniffin, K. M., \& Scalise Sugiyama, M. (2018). Toward a natural history of team sports. Human Nature, 29(3), 211-218. https://doi.org/10.1007/s12110-018-9322-6

Kobach, M. J., \& Weaver, A. J. (2012). Gender and empathy differences in negative reactions to fictionalized and real violent images. Communication Reports, 25(2), 51-61. https://doi.org/10.1080/08934215.2012.721087

Koskina, A., Campbell, I. C., \& Schmidt, U. (2013). Exposure therapy in eating disorders revisited. Neuroscience and Biobehavioral Reviews, 37(2), 193-208. https://doi.org/10.1016/j.neubiorev.2012.11.010

Koster, E. H. W., Crombez, G., Van Damme, S., Verschuere, B., \& De Houwer, J. (2004). Does imminent threat capture and hold attention? Emotion (Washington, D.C.), 4(3), 312-317. https://doi.org/10.1037/1528-3542.4.3.312

Laura Turner. (2017, August 7). 'Psycho' for the anxious: Why horror movies bring me comfort. Catapult. https://catapult.co/stories/a-cure-for-fear-psycho-for-theanxious-why-horror-movies-bring-me-comfort

Lennard, D. (2014). Bad Seeds and Holy Terrors: The Child Villains of Horror Film. SUNY Press.

Liddon, L., Kingerlee, R., \& Barry, J. A. (2018). Gender differences in preferences for psychological treatment, coping strategies, and triggers to help-seeking. British Journal of Clinical Psychology, 57(1), 42-58. https://doi.org/10.1111/bjc.12147 
Linehan, M. (1993). Cognitive-behavioral Treatment of Borderline Personality Disorder. Guilford Press.

Ling, Y., Nefs, H. T., Morina, N., Heynderickx, I., \& Brinkman, W.-P. (2014). A metaanalysis on the relationship between self-reported presence and anxiety in virtual reality exposure therapy for anxiety disorders. PLoS ONE, 9(5), e96144. https://doi.org/10.1371/journal.pone.0096144

LoBue, V. (2009). More than just another face in the crowd: Superior detection of threatening facial expressions in children and adults. Developmental Science, 12(2), 305-313. https://doi.org/10.1111/j.1467-7687.2008.00767.x

LoBue, V., \& Rakison, D. H. (2013). What we fear most: A developmental advantage for threat-relevant stimuli. Developmental Review, 33(4), 285-303. https://doi.org/10.1016/j.dr.2013.07.005

Mack, D. (2020, March 3). Everyone is watching "Contagion," a 9-year-old movie about a flu outbreak. BuzzFeed News. https://www.buzzfeednews.com/article/davidmack/contagion-movie-coronavirus

Marks, I. fM., \& Nesse, R. M. (1994). Fear and fitness: An evolutionary analysis of anxiety disorders. Ethology and Sociobiology, 15(5), 247-261. https://doi.org/10.1016/0162-3095(94)90002-7

Martin, G. N. (2019). (Why) do you like scary movies? A review of the empirical research on psychological responses to horror films. Frontiers in Psychology, 10, 2298. https://doi.org/10.3389/fpsyg.2019.02298 
Mobbs, D., Hagan, C. C., Dalgleish, T., Silston, B., \& Prévost, C. (2015). The ecology of human fear: Survival optimization and the nervous system. Frontiers in Neuroscience, 9. https://doi.org/10.3389/fnins.2015.00055

Morin, O., Acerbi, A., \& Sobchuk, O. (2019). Why people die in novels: Testing the ordeal simulation hypothesis. Palgrave Communications, 5(1), 1-10. https://doi.org/10.1057/s41599-019-0267-0

Nairne, J. S., Thompson, S. R., \& Pandeirada, J. N. S. (2007). Adaptive memory: Survival processing enhances retention. Journal of Experimental Psychology. Learning, Memory, and Cognition, 33(2), 263-273. https://doi.org/10.1037/0278$\underline{7393.33 .2 .263}$

Nave, G., Rentfrow, J., \& Bhatia, S. (2020). We are what we watch: Movie plots predict the personalities of those who "like" them. PsyArXiv. https://doi.org/10.31234/osf.io/wsdu8

Nesse, R. M. (2019). Good Reasons for Bad Feelings: Insights from the Frontier of Evolutionary Psychiatry. Penguin.

Neuberg, S. L., Kenrick, D. T., \& Schaller, M. (2011). Human threat management systems: Self-protection and disease avoidance. Neuroscience and Biobehavioral Reviews, 35(4), 1042-1051. https://doi.org/10.1016/j.neubiorev.2010.08.011

Newman, M. G., \& Llera, S. J. (2011). A novel theory of experiential avoidance in generalized anxiety disorder: A review and synthesis of research supporting a contrast avoidance model of worry. Clinical Psychology Review, 31(3), 371-382. https://doi.org/10.1016/j.cpr.2011.01.008 
Pai, A., Suris, A. M., \& North, C. S. (2017). Posttraumatic Stress Disorder in the DSM-5: Controversy, Change, and Conceptual Considerations. Behavioral Sciences (Basel, Switzerland), 7(1). https://doi.org/10.3390/bs7010007

Paszkiewicz, K., \& Rusnak, S. (2020). Final Girls, Feminism and Popular Culture. Springer Nature.

Penkunas, M. J., \& Coss, R. G. (2013). Rapid detection of visually provocative animals by preschool children and adults. Journal of Experimental Child Psychology, 114(4), 522-536. https://doi.org/10.1016/j.jecp.2012.10.001

Pergamin-Hight, L., Naim, R., Bakermans-Kranenburg, M. J., van IJzendoorn, M. H., \& Bar-Haim, Y. (2015). Content specificity of attention bias to threat in anxiety disorders: A meta-analysis. Clinical Psychology Review, 35, 10-18. https://doi.org/10.1016/j.cpr.2014.10.005

Rashtbari, A., \& Saed, O. (2020). Contrast avoidance model of worry and generalized anxiety disorder: A theoretical perspective. Cogent Psychology, 7(1), 1800262. https://doi.org/10.1080/23311908.2020.1800262

Rauch, S. A. M., Yasinski, C. W., Post, L. M., Jovanovic, T., Norrholm, S., Sherrill, A. M., Michopoulos, V., Maples-Keller, J. L., Black, K., Zwiebach, L., Dunlop, B. W., Loucks, L., Lannert, B., Stojek, M., Watkins, L., Burton, M., Sprang, K., McSweeney, L., Ragsdale, K., \& Rothbaum, B. O. (2020). An intensive outpatient program with prolonged exposure for veterans with posttraumatic stress disorder: Retention, predictors, and patterns of change. Psychological Services, No Pagination Specified-No Pagination Specified. https://doi.org/10.1037/ser0000422 
Rosa-Alcázar, A. I., Sánchez-Meca, J., Gómez-Conesa, A., \& Marín-Martínez, F. (2008). Psychological treatment of obsessive-compulsive disorder: A metaanalysis. Clinical Psychology Review, 28(8), 1310-1325. https://doi.org/10.1016/j.cpr.2008.07.001

Salovey, P., Mayer, J. D., Goldman, S. L., Turvey, C., \& Palfai, T. P. (1995). Emotional attention, clarity, and repair: Exploring emotional intelligence using the Trait Meta-Mood Scale. In Emotion, disclosure, \& health (pp. 125-154). American Psychological Association. https://doi.org/10.1037/10182-006

Salters-Pedneault, K., Tull, M. T., \& Roemer, L. (2004). The role of avoidance of emotional material in the anxiety disorders. Applied and Preventive Psychology, 11(2), 95-114. https://doi.org/10.1016/j.appsy.2004.09.001

Scalise Sugiyama, M. (2001). Narrative theory and function: Why evolution matters. Philosophy and Literature, 25(2), 233-250. https://doi.org/10.1353/phl.2001.0035

Scalise Sugiyama, M. (2021). The fiction that fiction is fiction. ASEBL Journal, 15, 8-11. Scalise Sugiyama, M., Mendoza, M., White, F., \& Sugiyama, L. (2018). Coalitional play fighting and the evolution of coalitional intergroup aggression. Human Nature, 29(3), 219-244. https://doi.org/10.1007/s12110-018-9319-1

Schaefer, A., Nils, F., Sanchez, X., \& Philippot, P. (2010). Assessing the effectiveness of a large database of emotion-eliciting films: A new tool for emotion researchers. Cognition and Emotion, 24(7), 1153-1172. https://doi.org/10.1080/02699930903274322

Schaumberg, K., Reilly, E. E., Gorrell, S., Levinson, C. A., Farrell, N. R., Brown, T. A., Smith, K. M., Schaefer, L. M., Essayli, J. H., Haynos, A. F., \& Anderson, L. M. 
(2021). Conceptualizing eating disorder psychopathology using an anxiety disorders framework: Evidence and implications for exposure-based clinical research. Clinical Psychology Review, 83, 101952.

https://doi.org/10.1016/j.cpr.2020.101952

Schneider, S. J. (Ed.). (2004a). Horror Film and Psychoanalysis: Freud's Worst Nightmare. Cambridge University Press. https://doi.org/10.1017/CBO9780511497742

Schneider, S. J. (Ed.). (2004b). Horror Film and Psychoanalysis: Freud's Worst Nightmare. Cambridge University Press. https://doi.org/10.1017/CBO9780511497742

Scrivner, C. (2021). The psychology of morbid curiosity: Development and initial validation of the morbid curiosity scale. PsyArXiv. https://doi.org/10.31234/osf.io/xug34

Scrivner, C. (2021). An infectious curiosity: Morbid curiosity and media preferences during a pandemic. Evolutionary Studies in Imaginative Culture, 5(1). $\underline{\text { https://esiculture.com/an-infectious-curiosity-morbid-curiosity-and-media- }}$ preferences-during-a-pandemic

Scrivner, C., Johnson, J. A., Kjeldgaard-Christiansen, J., \& Clasen, M. (2021). Pandemic practice: Horror fans and morbidly curious individuals are more psychologically resilient during the COVID-19 pandemic. Personality and Individual Differences, 168, 110397. https://doi.org/10.1016/j.paid.2020.110397

Shore, T., Kadosh, K. C., Lommen, M., Cooper, M., \& Lau, J. Y. F. (2017). Investigating the effectiveness of brief cognitive reappraisal training to reduce fear in 
adolescents. Cognition and Emotion, 31(4), 806-815.

https://doi.org/10.1080/02699931.2016.1159542

Shu, J., Hassell, S., Weber, J., Ochsner, K. N., \& Mobbs, D. (2017). The role of empathy in experiencing vicarious anxiety. Journal of Experimental Psychology. General, 146(8), 1164-1188. https://doi.org/10.1037/xge0000335

Spielberger, C. D. (1966). Theory and research on anxiety. Anxiety and behavior, 1(3).

Spokas, M., Luterek, J. A., \& Heimberg, R. G. (2009). Social anxiety and emotional suppression: The mediating role of beliefs. Journal of Behavior Therapy and Experimental Psychiatry, 40(2), 283-291.

https://doi.org/10.1016/j.jbtep.2008.12.004

Steen, F., \& Owens, S. (2001). Evolution's Pedagogy: An Adaptationist Model of Pretense and Entertainment. Journal of Cognition and Culture, 1(4), 289-321. https://doi.org/10.1163/156853701753678305

Strizhakova, Y., \& Krcmar, M. (2007). Mood Management and Video Rental Choices. Media Psychology, 10(1), 91-112. https://doi.org/10.1080/15213260701301152

Suddendorf, T., \& Corballis, M. C. (2007). The evolution of foresight: What is mental time travel, and is it unique to humans? The Behavioral and Brain Sciences, 30(3), 299-313; discussion 313-351. https://doi.org/10.1017/S0140525X07001975

Tamborini, R., \& Stiff, J. (1987). Predictors of horror film attendance and appeal: An analysis of the audience for frightening films. Communication Research, 14(4), 415-436. https://doi.org/10.1177/009365087014004003 
Telch, M., Cobb, A., \& Lancaster, C. (2013). Exposure therapy for anxiety disorders: Procedural variations, clinical efficacy, and change mechanisms. In P. Emmelkamp \& T. Ehring (Eds.), International handbook for anxiety disorders (Vol. 2, pp. 717-756). Wiley-Blackwell.

The Numbers. Box Office Performance for Horror Movies in 2019. Retrieved February 25, 2021, from https://www.the-numbers.com/market/2019/genre/horror

Thompson, R. J., Boden, M. T., \& Gotlib, I. H. (2017). Emotional Variability and Clarity in Depression and Social Anxiety. Cognition \& Emotion, 31(1), 98-108. https://doi.org/10.1080/02699931.2015.1084908

Turley, Jeffrey M., \& Derdeyn, A. P. (1990). Use of a horror film in psychotherapy. Journal of the American Academy of Child \& Adolescent Psychiatry, 29(6), 942945. https://doi.org/10.1097/00004583-199011000-00018

Turley, JEFFREY M., \& Derdeyn, A. P. (1990). Case study: Use of a horror film in psychotherapy. Journal of the American Academy of Child \& Adolescent Psychiatry, 29(6), 942-945. https://doi.org/10.1097/00004583-199011000-00018

Turner, L. (2017, August 7). 'Psycho' for the anxious: Why horror movies bring me comfort. Catapult. https://catapult.co/stories/a-cure-for-fear-psycho-for-the-anxious-why-horrormovies-bring-me-comfort

Vine, V., \& Aldao, A. (2014). Impaired emotional clarity and psychopathology: A transdiagnostic deficit with symptom-specific pathways through emotion regulation. Journal of Social and Clinical Psychology, 33(4), 319-342. https://doi.org/10.1521/jscp.2014.33.4.319

Wertz, A. E. (2019). How plants shape the mind. Trends in Cognitive Sciences, 23(7), 528-531. https://doi.org/10.1016/j.tics.2019.04.009 
Where's The Jump? - A Movie Jump Scare Database. (n.d.). Retrieved February 1, 2021, from https://wheresthejump.com/

Wilson, A. C., Aldao, A., \& Cheavens, J. (2018). Appraising reappraisal: Exploring its role in the context of behavioral exposure for contamination fears. Journal of Clinical Psychology, 74(9), 1583-1593. https://doi.org/10.1002/jclp.22613

Yousaf, O., Grunfeld, E. A., \& Hunter, M. S. (2015). A systematic review of the factors associated with delays in medical and psychological help-seeking among men. Health psychology review, 9(2), 264-276.

https://doi.org/10.1080/17437199.2013.840954

Zuckerman, M. (1994). Behavioral expressions and biosocial bases of sensation seeking (pp. xiv, 463). Cambridge University Press.

Zuckerman, M., \& Litle, P. (1986). Personality and curiosity about morbid and sexual events. Personality and Individual Differences, 7(1), 49-56.

https://doi.org/10.1016/0191-8869(86)90107-8 